\title{
MANAGING THE NEW ZEALAND ECONOMY AT A TIME OF NATURAL DISASTER
}

\author{
R. L. Knight * \\ Presented at the conference on \\ INFORMATION NEEDS OF THE EARTHQUAKE INSURANCE INDUSTRY \\ held in Christchurch, November 1989
}

\section{INTRODUCTION}

New Zealand is exposed to quite a wide variety of potential natural disasters, perhaps to a greater extent than most other countries. In recent memory, we have seen significant earthquakes, landslips, storms, droughts and floods - some of which have caused quite extensive local damage. Some other threats, such as a major eruption or a tsunami, could become a reality at any time. However, we have not so far had the experience of a major natural disaster on a scale which could seriously disrupt the whole economy, or even just one of our major cities. Disasters such as a major earthquake in Wellington, an eruption in Auckland, or a storm which caused serious nationwide damage to structures and to infrastructure would involve not only the conventional needs to safeguard life, maintain social welfare and repair damage, but would also raise significant economic management issues that we have not had to deal with before. Moreover, it could be difficult to draw any clear lessons from international experiences of similar disasters, since they are rare, and all tend to have unique characteristics which may not apply in New Zealand's situation.

This paper surveys some of the issues involved in formulating an economic policy response to a natural disaster. It needs to be stated at the outset that it is simply not possible or sensible to plan in detail for every possible contingency, for a number of related reasons. First, and most obviously, major disasters are extremely rare. It makes little sense to put a lot of resources into planning for events which have very low probabilities of occurring - in the same sort of way that it makes little sense to keep a large army in peace-time. Secondly, to the extent that planning is desirable, it should be focused on those aspects of a disaster which would require an immediate response. The primary emphasis of civil defence activities on

* Deputy Governor,

Reserve Bank of New Zealand promoting public safety and welfare is, in this context, entirely appropriate. In the area of economic management, by contrast, there are few areas where responses would need to be determined as a matter of real urgency. This leads to the third point - that the design of policy responses should ideally be based on the fullest possible information and analysis if they are to be robust and appropriate. Disasters can vary so widely in their severity, location and effects that it is axiomatic that responses will have to be to a considerable extent situational. There is an obvious trade-off between the desirability of responding rapidly when needs are most acute, and the wish to ensure that the responses are optimally targeted which would normally require a more considered approach - but there will be less tension in this trade-off in the economic area than, for example, in the public health area. Finally, it is, no doubt, a truism that the world is continually changing, but it is not one that we can ignore. Responses developed in advance of a disaster are dependent on a large number of assumptions about the nature and effects of the disaster, and the broader environment within which these are embedded. These assumptions can rapidly become inaccurate or invalid over time - so that, in practice, the first task in disaster management would be to review - and modify - the disaster management plan.

While it may not be sensible, for the above reasons, to invest too much in detailed planning for the management of a natural disaster, it is nevertheless important to give some thought to the nature of the issues that are likely to arise, and the kinds of processes that might be used to handle them. While the actual decisions flowing from a disaster may vary considerably according to the circumstances, the issues likely to be considered and the processes likely to be used in reaching those decisions may be subject to much less variance. Moreover, they are applicable, to a considerable extent, to a broad range of 
emergencies - not just those resulting from natural disasters.

The remainder of this paper therefore gives its primary focus to the issues and processes involved in managing the consequences of a natural disaster. The discussion is motivated essentially by disasters of the geological or meteorological types: some, but not all, of the analysis would readily carry over into disasters arising from public health, political, or economic shocks, although these would obviously have some distinctive elements. It also focuses mainly on "sudden" disasters, rather than "creeping" natural disasters such as the greenhouse effect, drought, etc. Finally, it should be noted that the paper provides a central banker's perspective on the issues: and while - traditionally at least - central bankers have been expected to be experts on everything, especially financial crises, the topic is so very broad that it is not possible to do justice to all the issues involved. The treatment should be recognised as selective, and as being biased towards financial matters.

The following sections discuss, firstly, and very briefly, the possible initial effects of a natural disaster, and then the possible financial and economic effects. These sections provide a basis for considering the issues and processes involved in determining and implementing required responses to the emergency.

\section{INITIAL EFFECTS}

The initial effects of a natural disaster can be split into two main areas: the direct or physical effects, and the derived or functional effects:

\section{(a) Direct Effects}

These can be summed up as follows:

- Partial or total damage to people.

- Partial or total loss-of-use of offices/factories/ houses/schools/hospitals/equipment.

- Disruptions to private and public transportation of all types.

- Communications failures, including domestic radio and television and domestic and international telecommunications services.

- Losses of energy supplies such as electricity and gas.

\section{(b) Derived Effects}

Some of the second-round effects of a natural disaster are:

- All of the above physical disruptions could contribute to significant disruption of the "machinery of Government". Key personnel, including the Governor General, typists, mayors, computer operators and MPs could be either incapacitated, or physically prevented from reporting for duty. Even if they were at their desks, they might be unable to function effectively because of equipment problems, inability to obtain adequate information, doubts about their authority to take decisions, and so on.

- For similar reasons, private individuals and businesses could also find that their normal decision-making processes were disrupted. Boards of Directors could be unable to meet, or deprived of a quorum; and businesses might not be able to obtain adequate expert advice on how best to respond to the emergency. Individuals could similarly find their access to information, advice and various transaction services frustrated.

- Another consequence of a natural disaster could be the emergence of significant public health, welfare and law-and-order issues - some of which could, in turn, aggravate the disruption of private and government business while also escalating the need for a swift and sure policy response.

- Individuals could face substantial conflicts between their duties to their families, their concern to protect their property, and their obligations to employers. Many people will not put their work before their homes if a serious situation exists, and indemnities against property losses (as provided for in the Civil Defence Act in some cases) will not entirely alleviate this problem.

It is, of course, highly unlikely that all of the above direct and indirect effects would generally prevail on a nationwide basis. If they did, it would imply an extent of disaster which could permanently change the whole nature of our society. The more likely outcomes are that there could be intense damage in one area, but much of the nation would still be able to function pretty much as normal; or, alternatively (most obviously in the case of a storm), there could be nationwide damage and disruption but at a more superficial and quickly-repairable level. In both of these cases, it is possible to envisage a fairly rapid restoration of key economic management functions, but it is hard to generalise and this should not be taken for granted.

It is fairly obvious that there could be some significant distinctions between, say, Auckland- and Wellington-based disasters. A Wellington disaster could seriously disrupt the "machinery of Government" at all levels - legislative, executive, judicial and bureaucratic - and would also have a major impact on financial markets, which are largely Wellington-based. There would be considerable hiccups - at least - in the transfer of these services to alternative locations given the people/equipment/-records required, but it could be possible to re-establish some basic services either inside or outside Wellington reasonably quickly. An Auckland disaster, by contrast, would have its most 
serious economic impact on the productive base and distribution systems, and these are obviously much less transportable in the short term, and could involve. significantly longer repair/reconstruction periods.

\section{FINANCIAL EFFECTS AND ISSUES}

The financial system could be severely disrupted, either locally or nationally, by a natural disaster. Many bank branches could remain closed, cheques and other forms of payment might not be cleared, and ATM and EFTPOS services might not be available. Brief disruptions to "retail" payments systems need not, in themselves, be much of a cause for concern, as people would find a number of ways to adapt, particularly for small transactions. Disruptions to payments systems (cheque or electronic) could increase the use of cash for payments, and banks together with the Reserve Bank might need to look at ways of supplying more currency to the system to meet any increased demand. However, in practice, the restoration of at least some basic (cheque) clearing services could be fairly rapid provided physical communications to alternative processing centres were open. Restoration of electronic services could take a little longer if cable networks were extensively damaged. Overall, however, it is difficult to envisage circumstances where disruptions to "retail" transactions/payments services, on their own, would seriously constrain the economy: other factors are likely to be considerably more important.

Trading in financial markets - the domestic money market and the foreign exchange market - could be significantly disrupted, for both technical and economic reasons. At a technical level, trading requires that people, communications facilities and basic banking settlement services all have to be in operation to some extent, and these requirements may be able to be met reasonably quickly obiously, in any cities unaffected. However, the main difficulty for many traders could be in getting comprehensive information together on the scope of the disaster, the Government and private sector responses, and their own trading positions. There is likely to be a great deal of uncertainty for a period about the extent to which the exchange rate and interest rates need to adjust in the new situation. This will mean that markets could be very volatile and disorderly - and could, in the limit, fail to function because of uncertainty about the appropriate trading positions to take. In practice, of course, both the technical factors and the economic uncertainties will often operate together.

In principle, the Government and the Reserve Bank could play a very useful role in helping to stabilise and resuscitate financial markets through their own trading activities. In practice, however, matters may not be very straightforward, since officials and Ministers would probably face exactly the same technical and informational problems as private traders and they would be equally uncertain about the appropriate exchange rate and/or interest rate targets to aim for. THe appropriate emphasis in the initial stages would be to gather and disseminate as much relevant information as possible on the situation, so that an informed consensus could be established on the adjustments required. As with the payments system, a brief period of disruption to financial market trading is unlikely to have any significant effects on the real economy - and closing the markets (formally or informally) for a period until this consensus starts to emerge may well be more sensible than adopting some rapid, but illinformed, responses.

One of the more worrying potential financial consequences of a natural disaster is the possibility of widespread loss-of-confidence in the safety of some banks or financial institutions. There would be two sources of pressure on banks' balance sheets in a disaster situation: first, the value of many of their own real assets and of their loans in the disaster area, could deteriorate substantially. Loans could fall in value because of the reduced ability to repay of some borrowers, and/or because of reductions in the value of collateral. Some of these effects could be alleviated by insurance arrangements, but in extreme cases a disaster could threaten the solvency of a bank. Secondly, banks' customers could be expected to respond to a disaster by withdrawing cash balances and applying for emergency credit facilities in order to get repairs and reconstruction underway rapidly. This could put considerable pressure on the liquidity of banks affected, particularly if financial markets were still unsettled and normally-marketable securities were difficult to sell. The Reserve Bank would need to monitor any developments along these lines extremely closely, and might need to make emergency liquidity assistance available outside of its normal policy.

Some of these considerations also apply with respect to the insurance industry, and to the disaster (and life) insurers in particular. There would be pressure on them for rapid disbursements to both individuals and businesses for damage limitation, repairs, and reconstruction, and the insurers would have to liquify reserve assets and draw on reinsurance arrangements fairly quickly. This, in turn, would generally be possible only if financial markets and banking facilities were functioning normally, but some Government and/or Reserve Bank involvement and assistance might still be appropriate given the very large financial flows which could be involved.

\section{GENERAL ECONOMIC EFFECTS AND ISSUES}

The broader economic effects of a major natural disaster would be pervasive. They include:

- Losses of production.

- Reductions of income and wealth, 
- Dissaving: increased demand for credit and withdrawals of deposits, etc.

- Upward pressure on interest rates.

- Pressure on imports to relieve supply problems, replace equipment, etc.

- Pressure on foreign borrowing to relieve credit constraints.

- Probably a fall in the real exchange rate (although this is ambiguous analytically).

- Some sharp relative price changes probably, but overal1 inflationary impact also ambiguous, depending on the level and structure of demand.

Two general points about these effects are of interest: first, while there would be considerable variations in the direct effects of a disaster on different regions, many of the indirect effects would be essentially more national than regional in character. In one sense, this means that we would all share some of the burden of paying for a disaster simply through the normal operations of markets. From an economic management viewpoint, it is clear that any policy responses to a disaster should not be determined in isolation: rather, they have to be embedded, from their inception, within a broad macroeconomic framework which appropriately balances the needs and pressures arising from the disaster against the normal needs and pressures from other sources. This point is elaborated later in the paper.

Secondly, some of the economic effects of a disaster would be "permanent", in the sense that the economy would never be entirely the same again, but the bulk of the effects could probably be regarded as mainly temporary in nature. However, depending on the nature and scope of the disaster, even "temporary" disturbances could. last for a very long time. The main implication of this aspect is that the economic management response to a national disaster involves more than just a set of initial decisions: the response will, in fact, have to be evolutionary as adjustment and reconstruction proceed.

Against this general background, we turn to consider some of the more specific economic management issues that could arise from a disaster, mainly beyond the point where the "dust has settled".

\section{(a) Fiscal Management Issues}

An issue which would need to be addressed quickly by the Government would be the adequacy of existing disaster insurance arrangements, and the treatment of uninsured losses. In any situation where the disaster insurer(s) do not have adequate resources to meet their obligations, or where cover is inadequate to enable the insured parties to restore or replace all their assets, then the Government has to decide on the extent to which it is prepared to fill the gap. This decision will be affected by a number of factors - including the Government's de jure and de facto obligations, flows of charitable and external assistance, and the nature and scope of the disaster - but, at the end of the day, the issue may be more of a moral one than an economic or legal one.

The Government could, of course, try to reduce its potential exposure to this sort of problem by compelling people and businesses to insure fully against disasters - but, for completeness, this would have to include losses of income and intangible assets as well as the real property currently emphasised. This may be unrealistic: and it is not necessarily efficient for the Government to shift all the risk away from itself in any case. Moreover, the exposure could only be removed completely if the insurers were in a position to mobilise sufficient funds to pay-out on all conceivable disasters.

Most people are probably fairly comfortable with the notion that the victims of serious misfortune should be assisted by the community as a whole, and that the Government may have some comparative advantage in doing this. However, it is also clearly important to avoid the moral hazard problems implicit in this position: that people and businesses will not be encouraged to maintain adequate disaster insurance, or adopt appropriate riskcontrol practices, if they feel confident that the Government will pick up the tab when things go sour.

The issue of how much implicit insurance should be offered by the Government is clearly not a straightforward one, either in respect of the design of disaster insurance arrangements, or in determining the actual response to a disaster.

A somewhat related point is the extent to which the Government is directly exposed to disaster losses. Up until now, the Government has mostly carried its own risk with respect to losses to its own property, but this situation is starting to change. To the extent that Government property remains uninsured, the reconstruction of damaged property would be a direct burden on the budget.

The Government's taxation revenues could be significantly reduced by a disaster. because of losses of income and production, reduced sales, and capital and inventory write-offs. Moreover, dividends from SOEs etc. could fall substantially if cash flows had to be diverted into rehabilitation.

Most of the pressures on Government expenditure would be upwards following a disaster - not only because of any implicit insurance payments or uninsured direct losses as mentioned above, but also because of additional welfare and housing assistance, additional funding for medical resources and facilities and the ACC, assistance to local authorities and the National Roads Board for infrastructural rehabilitation, and so on.

The overall pattern is fairly clear: the effect of a major disaster would be to 
widen the budget deficit, possibly very substantially and for a significant period. The main issues arising from this would be the choice of the mix of taxation and borrowing to fill the gap and, in the case of borrowing, whether it should be sourced from domestic or external sources.

\section{(b) Monetary Management Issues}

In principle, a natural disaster should not involve any change to the underlying aim of monetary policy, which is to keep inflation very low. Inflation resulting from a disaster would be at least as unwelcome as inflation resulting from any other cause, and would aggravate the possible problems of financial stability already mentioned. Moreover, it could also cause serious problems if property replacement costs escalated to a level well in excess of insurance payouts.

In practice, the implementation of monetary policy in a period of significant disruption would not be at all straightforward. It is inevitable that some significant supply shortages and bottlenecks would arise, and these could lead to sharp upward movements in the prices of some commodities. Patterns of demand could also shift in ways which would induce significant price changes - both upward and downward. It would definitely not be an appropriate function of monetary policy to seek to prevent these relative price changes occurring - and this would not be possible in the short term in any case. But it would be important to ensure that such price shifts did not feed through into a generalised round of price and wage increases. In other words, the trick would be to allow for one-off structural price shifts to occur, but not for any secondround inflation.

A further complication is that a number of the proximate indicators of monetary policy - interest rates, exchange rates, and money and credit demands - could, as already noted, be severely distorted by a natural disaster, and they could be very difficult to interpret for a period. In fact, of course, reliable and complete information on some of these indicators - as well as on price movements - might not even be available. The Reserve Bank would certainly need to use all its wits in trying to judge the tightness of its policy on the basis of these indicators.

\section{(c) Other Economic Management Issues}

outside the monetary and fiscal areas, the main economic management issues arising from a natural disaster would probably lie in commodity and labour markets. In some cases, the supply and/or demand shocks could be so large that some markets would fail completely - i.e. potential purchasers would be unable to find the commodities or labour services they required at any price; or, at the other extreme, potential sellers could find that the market for their products had completely evaporated. In less extreme cases, the markets could still continue to operate, but with very sharp price (or wage) movements involved. Alternatively, if there was a degree of inertia in price adjustments, there would be unsatisfied demand for certain commodities and services, and various forms of queuing and rationing would develop.

Developments such as these are not necessarily matters demanding a response from the Government. In particular, where sharp price increases reflect a permanent or long-term supply disruption, then they must be accepted - and even welcomed: the price change, in this case, reflects the new scarcity value of the commodity and, in general, allocations through the price system will be efficient. However, the situation becomes a little less clear with supply (or demand) disruptions that are strictly temporary in nature, and where a price increase is not necessary to draw-out the supply response required. It becomes even murkier where the commodities concerned are "essential" goods, especially things like food or pharmaceuticals: in this case, the issue is whether efficient allocations are also sufficiently equitable. No one - in New Zealand at least - would readily accept a situation where the rich could eat well, but the poor would starve. However, in deciding that some form of Government intervention could be appropriate in such situations, considerable care needs to be taken with the design and operation of such interventions.

In fact, a number of forms of intervention are usually possible. First, the Government could directly enter the market concerned as a supplier. While it will not normally hold any appropriate commodity inventories in advance of a disaster, it might be able to obtain supplies from other parts of the nation or from overseas to put into the market. The main issue here would be whether the Government itself could do this job more efficiently than anyone else. In the labour services area, the Government might be able to divert some of its own labour resources - either within the affected area or from outside it - to help fill any critical gaps.

Secondly, the Government could consider relaxing any impediments to similar forms of adjustment by the private sector. For example, import controls - if existent - could be temporarily waived, or immigration restrictions could be eased in order to allow the build-up of an adequate reconstruction labour force.

Thirdly, if equity concerns were particularly prominent, the Government could consider providing financial compensation to the principal victims.

Finally, of course, the Government could, in some cases, seek to regulate the markets directly - through price controls, formal rationing systems, compulsory acquisition of essential commodities, etc. This has been a typical response to emergencies such as wars in the past.

The choices among these alternatives will need to be weighed carefully in any 
practical situation. It is important that the general efficiency arguments are not lost sight of when decisions are made: we now have a lot of evidence that the costs of trampling on the price system can be very high, and the benefits often more illusory than real. In this context, it would also be necessary to weigh the practical ability of the Government to operate an effective allocation system for. key commodities. The presumption really has to be that direct controls on markets should be regarded very much as a last resort. It is a last resort which, in some situations could be reached very quickly, but must be based on an objective rejection of the alternatives, and narrowly confined to those areas where it is genuinely essential.

\section{ORGANISATIONAL AND PROCEDURAL MATTERS}

The National Civil Defence Plan provides quite a lot of detail on the responsibilities of different Government departments and other organisations in dealing with a natural disaster. All are responsible for continuing their normal functions - at least those which have priority - and some are required to accept extra special duties as well. Various emergency powers can be invoked under the Civil Defence Act, or other Acts where appropriate. Provisions exist for Parliament to be assembled at short notice. centralised co-ordination and control would be primarily the responsibility of the Director of Civil Defence in the response phase, and of the Domestic and External Security co-ordinator in the recovery phase.

In the area of economic management, the moves towards deregulation in recent years, and the repeal of the Economic Stabilisation Act in particular, mean that the Government now has much less in the way of powers of direct control over economic activity than it used to have. However, it is unlikely that this would impede the Government's economic response to a natural disaster in any substantial way, for several reasons. First, in these few areas where an immediate response may be deemed essential, it is likely that powers do still exist which could be used for the purpose. For example, if intervention in the foreign exchange market or the domestic financial markets is required, there is no legal impediment to the Reserve Bank undertaking this - although, in practice, the Bank might want or need the Government's blessing before it acted. Secondly, in most cases, the design of an appropriate economic response will take some time - information will need to be gathered and analysed before the decisions can be taken. Immediate action in most areas of economic policy will not be required - and might not even be desirable. Thirdly, where any gaps in the legal framework do become apparent, it should be possible for Parliament to fill them within the required time-scale, and in a way which is closely tailored to the demands of the actual situation. In all of these respects, a natural disaster can be fairly clearly distinguished from an emergency such as war, where more rapid action on a number of fronts could be required.

A detailed examination of the emergency powers available to the Government - their adequacy, the procedures involved, their coherence, and the appropriateness of the safeguards - is currently being conducted by the Law Commission. This examination should assist in identifying any important gaps in coverage, or any weaknesses in the constitutional apparatus, which could inhibit action being taken at the time necessary.

Most of the underlying principles of economic management will not change at all as a result of a disaster. Of course, the environment might have changed substantially and the disaster could have had large economic effects, but these do not alter the basic principles. It is worth stressing some of these, because they can too often be lost from sight in the heat of the moment:

(a) It is important to attack the causes of problems rather than their symptoms.

(b) Policy interventions should be minimal, i.e. no more than is strictly necessary to achieve the desired outcomes - in either their degree, or the time for which they are applied.

(c) A balanced approach must be followed. Recovery should not be pursued in a single-minded way which unduly threatens other important economic objectives.

(d) The techniques of intervention should use market forces as far as possible rather than seek to frustrate them.

(e) Consistency of response across different policy areas, and over time, is essential.

In practice, it may not always be possible to follow all of these principles closely, particularly in the early stages of response where information may be incomplete, markets may be dysfunctional, and the tradeoffs between different objectives may be particularly acute. But such difficulties would not constitute any excuse for ignoring the principles - a policy response which involved, say, a long-term, heavy-handed regulatory overreaction could itself have very serious economic costs, and must be avoided.

In principle, a natural disaster would not require any great changes in the procedures for determining and implementing economic policy. In practice, some expenditure decisions, for example, could well be made on an accelerated time scale, outside the normal budget process, and driven mainly by "physical" (rather" than economic) imperatives. In these circumstances, it might be necessary to upgrade the liaison and communication/co-ordination amongst departments and other relevant organisations, and establish some centralised monitoring arrangements. This would help, first, to ensure that the Government was always kept well-informed of the broad economic implications of a variety of specific decisions (some of 
which could be large in their own right), and thus kept in a position to determine any appropriate economic policy responses; and, secondly, to enable informed judgments to be made on priorities where necessary. Such arrangements would probably differ only in degree rather than substance from the current system; and, in particular, care would need to be taken to ensure that they did not lead to protracted delays in decision-making.

Finally, it should be emphasised that a great part of the response to a natural disaster will lie in the private sector and, as well as determining its own actions, much of the Government's effort will need to be directed to creating the right environment for appropriate and timely private sector responses to the emergency. In this context, the Government's public information role could be particularly important: the sooner the private sector gets reliable and comprehensive information on what has happened and what the Government is doing about it, the sooner they will be able to plan their own responses in confidence that they have full information.

of course, none of the processes involved in determining and implementing an economic management response to a natural disaster can commence until at least some of the machinery of Government is working, and the key departments and organisations have got sufficient people and resources to recommence operations. The process of reestablishing full-functionality is likely to be an uneven one and could take some time - particularly, of course, if the disaster is Wellington-based. Reestablishment of at least some basic infrastructure - e.g. transport, communications and energy supplies - would be a prerequisite for the re-establishment of most classes of government (and, of course, private) operations. The relocation of some functions and/or people to other centres could help in some cases, but it would be realistic to plan on the basis that substantial disruption could not really be avoided - the only issues would be how long it would last for, and what could be done to reduce this period to a minimum - given that other priorities may also exist.

\section{CONCLUSION}

In some respects, economic management following a natural disaster would not be intrinsically different from economic management at any other time. In practice, however, it could be a very complex and difficult business, because of:

- changes in the "real" economy

- disruption of the financial system

- incomplete information on the problems

- pressure for quick decisions/responses

- difficult conflicts between "ethical imperatives" and "economic realities"

- analytical complexity in understanding the characteristics of the changed economic structure.
Few of these problems can be addressed in any sensible way before a disaster occurs. They will all have to be worked through at the time, perhaps in a fairly pragmatic way in the initial stages, but guided by the principles discussed earlier. Overcoming the main physical disruptions caused by a disaster will generally be a prerequisite for determining the appropriate economic policy responses.

Some steps can, of course, be taken to reduce the potential economic effects of a disaster. Risks can be spread, regionally and internationally, through insurance and reinsurance. Areas or technologies particularly vulnerable to natural disasters can be avoided (although it may not be cost-effective to move the capital city now!). Risks can also be spread through regional diversification of operations, where economies of scale permit this. Key systems and records, which are essential to future operations, can be backed-up in a variety of ways. All such options have costs as well as potential benefits, of course, and it is difficult to weigh them given the low and uncertain probabilities of disaster occurrence. It would be neither sensible nor possible to seek to shift or eliminate all risks, but we are probably not erring too much in that direction at present.

However, in much the same way that the people who recover most rapidly from disease or accident are likely to be those who are fit and healthy in the first place, it may well be that the best economic preparation for a natural disaster would be to ensure that we always have a fit and healthy economy. If a disaster strikes when the inflation rate is low, the fiscal deficit is well under control, domestic and foreign debt levels are well within accepted bounds, the overseas reserve position is strong, companies and financial institutions have strong and diversified balance sheets, and resources can be reallocated flexibly, then the processes of financing and implementing recovery without causing severe strains will be immensely easier, and accomplished more quickly. of course, this is a point of wide application: the greater room to manoeuvre which is provided by a healthy economy helps to protect the economy and the people not only from natural disasters but also from shocks, disasters and emergencies of all types.

\section{FOOTNOTES}

The views expressed in this paper are strictly personal, and have not been endorsed by the Reserve Bank or the Government.

The merits, or otherwise, of current moves towards insuring Government property are not obvious. In its simplest terms, the choice is between paying for disasters ex ante (through premiums) or ex post (through additional borrowing costs). However, if moves towards insurance generate better management and control of risk, then there could be real benefits for the Government from the shift. 